\title{
The prevalence of macrovascular disease and lipid abnormalities amongst diabetic patients in Sri Lanka
}

\author{
Devaka J.S. Fernando, Sisira Siribaddana, Nilukshi Perera, Shironi Perera \\ and Deepthika de Silva
}

Sri Jayawardenepura General Hospital, Talapathpitiya, Nugegoda, Sri Lanka

\begin{abstract}
Summary: The prevalence of macrovascular disease and hyperlipidaemia was examined in $\mathbf{5 0 0}$ patients with non-insulin-dependent diabetes mellitus attending a diabetic clinic in a Sri Lankan teaching hospital and 250 controls matched for age and gender. Macrovascular disease was assessed using a modified World Health Organisation questionnaire and modified Minnesota coding of electrocardiogram recordings.

Twenty-one per cent of diabetic patients and $14.3 \%$ of controls had hypercholesterolaemia $(P<0.05)$. Macrovascular disease was present in $13.4 \%$ of diabetic patients and $8.2 \%$ of controls. Significant differences were seen in the prevalence of hypertension $(15.6 \%$ vs $4.8 \%, P<0.05)$, obesity $(16.2 \%$ vs $9.7 \%, P<0.05)$, peripheral vascular disease $(5.6 \%$ vs $2 \%, P<0.05)$ and electrocardiographic abnormalities $(12 \%$ vs $6 \%, P<0.05)$ in diabetic patients when compared to controls.

Hyperlipidaemia and macrovascular disease is common in non-insulin-dependent diabetic patients in Sri Lanka and accounts for significant morbidity.
\end{abstract}

\section{Introduction}

Ischaemic heart disease is said to be commoner amongst South Asians. It is well documented that the prevalence of coronary artery disease is commoner amongst Indian immigrants to the UK. ${ }^{1,2}$ Studies from Coventry, Leicester and London have demonstrated a higher risk of myocardial infarction amongst immigrants from the Indian subcontinent. ${ }^{3,4}$ Data from national morbidity and mortality statistics, ${ }^{2}$ hospital activity analysis ${ }^{3}$ and surveys ${ }^{5,6}$ show an excess of non-insulin-dependent diabetes mellitus amongst Asian immigrants to the United Kingdom. Diabetes mellitus has been established as a risk factor of sufficient quantitative importance to account for the excess cardiovascular mortality observed in immigrant Asians. ${ }^{7}$ The British Hyperlipidaemia Society ${ }^{8}$ and the European Atherosclerosis Society ${ }^{9}$ have suggested that individuals with total plasma cholesterol greater than $6.5 \mathrm{mmol} / 1$ who are at risk from premature cardiovascular disease should have active management aimed at reducing cholesterol towards the ideal level of $5.2 \mathrm{mmol} / \mathrm{l}$. The European Association for the Study of Diabetes (EASD) recommended that all patients with non-insulindependent diabetes should be screened for macrovascular disease and that control of diabetes should not be limited to glycaemic control alone. ${ }^{10}$

Correspondence: D.J.S. Fernando, M.D., M.R.C.P., 53A Flower Road, Colombo 7, Sri Lanka.

Accepted: 12 February 1993
In 1980 the World Health Organisation (WHO) estimated that diabetes mellitus affects 30 million persons worldwide but that information about incidence, prevalence, clinical features and longterm complications is inadequate in developing nations. ${ }^{11}$ This presents a major obstacle to rational health care planning in such countries for patients with diabetes. This paper reports on a study of macrovascular disease and hyperlipidaemia in Sri Lankan diabetic patients.

\section{Materials and methods}

Five hundred patients (198 females and 302 males) with non-insulin-dependent diabetes attending the Sri Jayawardenepura General Hospital were randomly selected, using a table of random numbers from a clinic register of 2,304 patients. A total of 250 non-diabetic control subjects ( 100 females and 150 males) stratified for age and gender were randomly selected from a register of 1,456 persons who had routine health screening at the hospital. Diabetes was diagnosed according to WHO criteria. ${ }^{11}$ All patients selected were from those treated with diet alone or with oral hypoglycaemic agents and onset of diabetes after 30 years of age. All patients with documented ketoacidosis were excluded from the study. Diabetes mellitus and impaired glucose tolerance was excluded in the controls by performing a $75 \mathrm{~g}$ oral glucose tolerance test. Patients with severe intercurrent 
illness requiring insulin therapy were excluded from the study.

A questionnaire was completed for each diabetic patient and control subject in which name, age, sex, present age and date of diagnosis of diabetes was recorded. Smoking status was recorded as smoker, ex-smoker or non-smoker.

The next section of the questionnaire was designed to assess the prevalence of macrovascular disease and was based on the WHO questionnaire. $^{12}$

The height without shoes was recorded in metres and weight in $\mathrm{kg}$. The body mass index (BMI) was calculated as $\mathrm{BMI}=$ weight $(\mathrm{kg}) /$ height (metres) ${ }^{2}$. Obesity was defined as BMI $>27$ for males and BMI $>25$ for females.

Blood pressure was measured after 5 minutes rest. A mercury sphygmomanometer with a $23 \times 14 \mathrm{~cm}$ cuff (bladder $23 \times 13 \mathrm{~cm}$ ) and a larger cuff for obese patients was used. Blood pressure was recorded in the right arm supported on a table at heart level with the patient seated. The average of three readings was recorded as the blood pressure. ${ }^{13}$ Hypertension was diagnosed according to WHO criteria. Those with systolic blood pressure greater than $160 \mathrm{mmHg}$ or diastolic blood pressure greater than $95 \mathrm{mmHg}$ or were taking antihypertensive medication were considered to have hypertension.

A 12-lead electrocardiogram (ECG) was recorded in all patients and controls and the results grouped into three categories using a modified Minnesota code. ${ }^{14}$ 'Coronary probable' included those with large $Q$ or $Q s$ waves and those with complete left branch bundle block (Minnesota code 1-1, 1-2 and 7-1). 'Coronary possible' included those with small $Q$ waves, ST segment abnormalities and $T$ wave abnormalities. All other ECGs were regarded as normal. This ECG classification has been used in several studies. ${ }^{15,16}$

Venepuncture was performed after a 14 hour fast in patients and controls. Blood glucose was assessed using the glucose oxidase method. Serum was separated from blood samples within 2 hours of collection. High density lipoprotein fraction was isolated for cholesterol analysis by the phosphotungstic acid and magnesium chloride method. Serum high density lipoprotein (HDL) cholesterol and total cholesterol were estimated by the CHOD-PAP method and total triglyceride by GPO-PAP method in an autoanalyser (Cobas Mira) using commercially available test kits (Boerhinger Mannheim GmbH, Germany). Low density lipoprotein (LDL) cholesterol was calculated in conventional units (mg/dl) using Friedwald's equation $^{17}$ as this equation cannot be applied directly to SI units. All lipid data were then converted to SI units. Hypercholesterolaemia was defined as total cholesterol greater than $6.5 \mathrm{mmol} / \mathrm{l}$ and hypertri- glyceridaemia as triglycerides greater than 2.25 $\mathrm{mmol} / \mathrm{l}$ as recommended by the European Atherosclerosis Society. ${ }^{8}$

Study data were stored in an IBM-compatible computer using D Base III plus software. Standard parametric and non-parametric tests were used (Mann-Whitney $U$-test, $\chi^{2}$-test).

\section{Results}

The mean ages for diabetic patients (198 females, 302 males) was $52 \pm 6.1$ years and for controls (100 females, 150 males) $53 \pm 5.3$ years.

The prevalence of those with abnormal ECG (coded 'coronary probable' and 'coronary possible') was higher amongst diabetic patients when compared to controls $(P<0.05)$ (Table I). Diabetic patients with abnormal ECG were older $(P<0.05)$ than diabetic patients with normal ECG. The prevalence of hypertension was higher in diabetic patients with an abnormal ECG $(P<0.05)$ (Table II). The total cholesterol was not significantly elevated in the diabetic patients with ECG abnormalities.

Symptoms suggestive of a myocardial infarction were present in $32(6.4 \%)$ patients (18 male/14 female). The ECGs of eight of these patients were coded as coronary probable and six as coronary possible. A total of $46(9.2 \%)$ patients had symptoms of angina. ECG coding for this group was? eight patients coronary probable and 16 patients coronary possible.

Symptoms suggestive of stroke were present in $18(3.6 \%)$ patients (10 male/8 female) and three $(1.3 \%)$ of controls (three males). Six patients had residual neurological signs of stroke while either

Table I Prevalence of vascular disease in diabetic and control groups

\begin{tabular}{lcc}
\hline & Diabetic & Controls \\
\hline Symptoms of infarction & $32(6.4)$ & $8(1.3)$ \\
Symptoms of angina & $46(9.2)$ & $15(6)$ \\
ECG 'coronary probable' & $18(3.6)$ & $5(2)$ \\
ECG 'coronary possible' & $42(8.4)^{*}$ & $10(4)$ \\
Abnormal ECG & $60(12)^{*}$ & $15(6)$ \\
Stroke & $18(3.6)$ & $3(1.3)$ \\
Peripheral vascular disease & $28(5.6)^{*}$ & $5(2)$ \\
Total cholesterol (mmol/l) & $5.8 \pm 1.1$ & $5.11 \pm 1.2$ \\
Hypercholesterolaemia & $105(21)^{*}$ & $36(14.3)$ \\
Triglycerides (mmol/l) & $1.58 \pm 1.1$ & $1.50 \pm 1.12$ \\
Hypertriglyceridaemia & $81(16.2)^{*}$ & $21(8.3)$ \\
Hypertension & $78(15.6)^{*}$ & $24(4.8)$ \\
Obesity & $81(16.2)^{*}$ & $23(9.7)$ \\
\hline
\end{tabular}

Figures are given as number $(\%)$ or mean \pm s.d. * $P<0.05$ compared to controls. 
Table II Diabetic patients with vascular complications

\begin{tabular}{lcccc}
\hline & $\begin{array}{c}\text { Mean age } \\
\text { (years) }\end{array}$ & $\begin{array}{c}\text { Duration } \\
\text { (years) }\end{array}$ & $\begin{array}{c}\text { Hypertension } \\
(\%)\end{array}$ & $\begin{array}{c}\text { Cholesterol } \\
(\mathrm{mmol} / \mathrm{l})\end{array}$ \\
\hline All diabetic & $52 \pm 6.1$ & 7.5 & 15.6 & $5.8 \pm 1.1$ \\
Abnormal ECG & $61 \pm 7.3^{*}$ & 12.7 & $36^{*}$ & $6.1 \pm 1.4$ \\
Claudication & $57 \pm 8.1^{*}$ & 11.8 & 25 & $6.12 \pm 1.23$ \\
Stroke & $58 \pm 4.1^{*}$ & 12.1 & 21 & $6.14 \pm 1.12$ \\
Controls & $53 \pm 5.3$ & - & $4.8^{*}$ & $5.11 \pm 1.2$ \\
\hline
\end{tabular}

${ }^{*} P<0.05$ compared to all diabetic patients.

hospital notes or discharge summaries were available in 14 patients documenting hemiplegia at time of admission to hospital. CT scans had been performed in seven patients and showed infarcts or haemorrhage.

A total of $19(3.8 \%)$ of diabetic patients and three $(1.3 \%)$ controls had symptoms of peripheral vascular disease. Nine $(1.8 \%)$ diabetic patients and two $(0.8 \%)$ controls had amputations of the lower limb for gangrene. One diabetic patient and one control patient had amputations due to trauma. These patients were not considered to have peripheral vascular disease. Six patients with peripheral vascular disease were coded as coronary probable and seven as coronary possible. Eight had symptoms suggestive of myocardial infarction and seven angina. Patients with peripheral vascular disease, cerebrovascular disease and ECG abnormalities were older and had a longer duration of diabetes (Table II).

No differences were observed in systolic blood pressure, total cholesterol and triglycerides between diabetic patients and controls. However, the prevalence of hypertension $(P<0.05)$, obesity $(P<0.05)$, hypercholesterolaemia $(P<0.05)$, and hypertriglyceridaemia $(P<0.05)$ was higher in diabetic patients when compared to controls (Table I).

No differences were observed regarding smoking status between the diabetic patients $(42 \%$ for males and $1.8 \%$ for females) and controls (44.1\% for males and $2 \%$ for females). The prevalence of smoking was higher amongst diabetic patients $(P<0.01)$ with abnormal ECG $(92 \%)$ compared to those with normal ECG $(30.8 \%)$.

\section{Discussion}

No published data are available for the prevalence of vascular disease amongst diabetic patients in Sri Lanka. The results of this study indicate that coronary vascular disease, peripheral vascular disease and cerebrovascular disease is more common amongst diabetic patients than age- and gender-matched controls. A study in Sri Lanka using the questionnaire alone estimated the prevalence of macrovascular disease in diabetic patients to be as high as $40 \% .{ }^{18}$ The questionnaire is not specific for vascular disease and has been known to overestimate the prevalence in previous studies. ${ }^{16}$

The ECG coding system is an epidemiological tool for comparing populations and is not a specific diagnostic method for coronary vascular disease. $Q$ waves are specific for coronary artery disease but are not sensitive. ST segment and $T$ wave changes may occur in patients pericardial disease, rheumatic heart disease and congenital heart disease. ST segment changes are therefore more sensitive but less specific for coronary artery disease. In the data analysis, patients or controls with diagnosed rheumatic or congenital heart disease or those who had heart murmurs were excluded.

Taking into account these limitations in the techniques used, those coded coronary probable, those with any ECG changes and who had a positive response to the sections of the questionnaire related to myocardial infarction or angina, had amputations or stroke could be considered to have macrovascular disease. The prevalence of macrovascular disease of $13.4 \%$ for diabetic patients and $8.2 \%$ for controls would reflect true prevalence.

In a random survey of males between the ages of 25 and 65 from a rural community, Mendis reported the prevalence of cholesterol levels over $6.5 \mathrm{mmol} / 1$ to be $22 \% .^{19}$ In this study the prevalence of hypercholesterolaemia in nondiabetic male controls aged $25-65$ years was $28 \%$. The NIH Consensus Development Conference ${ }^{20}$ and the WHO expert committee ${ }^{21}$ have stated that serum cholesterol has no major effect on the occurrence of coronary heart disease if the population mean is $4.5 \mathrm{mmol} / \mathrm{l}$ or less. In our results the population mean for control populations is $5.11 \mathrm{mmol} / 1$. However, since the control sample is small and was not selected from a communitybased register, no definite conclusions can be drawn about serum cholesterol on a national level. 
The mean cholesterol in diabetic patients was greater than $5.2 \mathrm{mmol} / 1$ (Table I) which is the threshold at which the European Atherosclerosis Society recommends lipid lowering diet for diabetic patients. A total of $21 \%$ of diabetic patients had cholesterol levels greater than $6.5 \mathrm{mmol} / 1$, the threshold at which drug treatment is recommended to those not responding to diet. ${ }^{9}$ The results of this study indicate that hypercholesterolaemia is common in diabetic patients in Sri Lanka.

The high prevalence of smoking is similar to that reported by Mendis ${ }^{19}$ and is a cause for concern as smokers have a three-fold higher risk of major ischaemic heart disease when compared to nonsmokers. ${ }^{22}$ This study has demonstrated an association between smoking and abnormal ECG in diabetic patients. No conclusions can be drawn on causative mechanisms from a cross-sectional study but prospective studies in the UK have shown that smoking carries a higher risk of coronary events. ${ }^{22}$

The demographic structure of the Sri Lankan population is changing rapidly with increasing proportions of senior citizens. We have shown previously that the prevalence of hypertension, ischaemic heart disease and peripheral vascular disease is higher in elderly diabetic patients ${ }^{23}$ and leads to disproportionately higher utilization of health service resources.

\section{References}

1. Marmot, M. \& Adelstein, A. Immigrant mortality in England and Wales 1970-1978. Population Trends 1983, 33: 14-17.

2. Balarajan, R., Bulusu, L., Adelstein, A.M. \& Shukla, V. Patterns of mortality among migrants to England and Wales from the Indian sub continent. $B r$ Med $J$ 1984, 289: 1185-1187.

3. Donaldson, L.J. \& Taylor, J.B. Patterns of Asian and non Asian morbidity in hospitals. Br Med J 1983, 286: 949-951.

4. Tunstall Pedoe, H., Clayton, D., Morris, J.N., Brigden, W. \& McDonald, L. Coronary heart attacks in East London. Lancet 1975, ii: 833-838.

5. Samantha, A., Burden, A.C. \& Fent, B. Comparative prevalence of non-insulin dependent diabetes in Asian and white caucasian adults. Diabetes Res Clin Pract 1987, 4: 1-6.

6. Mather, H. \& Keen, H. The Southall diabetes survey: prevalence of known diabetes in Asian and Europeans. $B r$ Med J 1985, 291: 1081-1084.

7. Woods, K.L., Samantha, A. \& Burden, A.C. Diabetes mellitus as a risk factor for acute myocardial infarction in Asians and Europeans. Br Heart J 1989, 62: 118-122.

8. Shepherd, J., Betteridge, D.J., Durrington, P.N. et al. Strategies for reducing coronary heart disease and desirable limits for blood lipid concentrations: guidelines for the British Hyperlipidaemia Association. Br Med J 1987, 295: 1245-1246.

9. The European Atherosclerosis Study Group. The recognition and management of hyperlipidaemia in adults: A policy statement of the European Atherosclerosis Society. Eur Heart J 1988, 9: 571-600.

10. Alberti, K.G.G.M. \& Gries, A. Management of non insulin dependent diabetes mellitus across Europe: a consensus view. Diabetic Med 1988, 5: 275-281.
We conclude that our data suggest that conventional risk factors such as hypertension, hypercholesterolaemia and obesity may play an important role in accounting for a higher prevalence of macrovascular disease in Sri Lankan diabetic patients.

Mortality from ischaemic heart disease is rising in Sri Lanka and with an ageing population this trend will persist. There is therefore a need for a policy to control risk factors. Successful implementation of such programmes has reduced morbidity and mortality from coronary heart disease in some parts of Finland. ${ }^{24}$ The results of this study indicate that the St Vincents declaration of the European Association of Diabetes should be implemented in Sri Lanka. The relevance of the European consensus and desk top guide for management of noninsulin-dependent diabetes ${ }^{25}$ has been questioned ${ }^{26}$ This study indicates that many of the recommendations given in the desk top guide are relevant and need to be implemented in Sri Lanka.

\section{Acknowledgements}

This study was supported by a research grant from MANSELL Sri Lanka.

11. WHO Expert Committee. Diabetes Mellitus, Second Report Technical report series 646. World Health Organisation, Geneva, 1980.

12. Jarrett, R.J., Keen, H. \& Grabauskas, V. The WHO multinational study of vascular disease in diabetes: 1 . General description. Diabetes Care 2: 175-186.

13. The 1988 Report Joint National Committee on Detection, Evaluation and Treatment of High Blood Pressure. Arch Intern Med 1988, 148: 1023-1038.

14. Prineas, R.J., Crow, R.S. \& Blackburn, H. The Minnesota Code Manual of Electrocardiographic Findings. Standards and Procedures for Measurement and Classification. John Wright, Bristol, 1962.

15. Samantha, A., Burden, A.C. \& Jagger, C. A comparison of the clinical features and vascular complications of diabetes between migrant Asians and Caucasians in Leicester UK. Diabetes Res Clin Pract 1991, 14: 205-214.

16. Keen, H. \& Jarret, R.J. The WHO multinational study of vascular disease in diabetes: 2. Macrovascular disease. Diabetes Care 1979, 2: 187-195.

17. Friedwald, W.T., Levy, R.J. \& Frerickson, D.S. Estimation of concentration of low density lipoprotein cholesterol in plasma without the use of preparative ultracentrifugation. Clin Chem 1972, 8: 499-502.

18. Vernidharan, J., De Silva, D.R., Jayaweera, G. \& Fernando, D.J.S. The prevalence of long term complications of diabetes in patients attending a diabetic clinic. Proceedings of the Annual Sessions of the Ceylon College of Physicians, 1991, pp. 4-5.

19. Mendis, S. Major risk factors of coronary heart disease in Sri Lankans. J Ceylon Coll Phys 1991, 24: 17-24. 
20. Consensus Development Conference Lowering Blood cholesterol to prevent heart disease. JAMA 1985, 253: 2080-2086.

21. Report of a WHO Expert Committee. Prevention of Coronary Heart Disease. WHO Technical report series 678. World Health Organisation, Geneva, 1982.

22. Shaper, A.G. \& Pockock, S.J. Risk factors for ischaemic heart disease in British men. Br Heart $J$ 1987, 57: 11-16.

23. Fernando, D.J.S., de Silva, C.E., Nanayakkara, S.F.R. \& Samarasinghe, H.H.R. Diabetes in the elderly in a developing country. Diabetes Res Clin Pract 1992, 15: 245-246.
24. Tuomelheto, J., Geboers, J., Salonen, J.T. et al. Decline in cardiovascular mortality in North Karelia and other parts of Finland. $\mathrm{Br} \mathrm{Med} J$ 1986, 293: 1068-1071.

25. Gries, F.A. \& Alberti, K.G.G.M. Management of noninsulin dependent diabetes mellitus in Europe: Consensus Statement. IDF Bull 1989, 32: 169-174.

26. Alberti, K.G.G.M. European consensus and desk top guide for management of NIDDM - are they relevant to the developing world? Int Diabetes Digest 1992, 3: 78-80. 